Prepared for the U.S. Department of Energy under Contract DE-AC05-76RL01830

\title{
WBN-1 Cycle 10 TPBAR Tritium Release, Deduced From Analysis of RCS Data
}

\section{TTP-1-3046-00, Revision 0}

MW Shaver,

MT Niehus

EF Love

February 2012

\section{Pacific Northwest}

NATIONAL LABORATORY

Proudly Operated by Battelle Since 1965 


\title{
DISCLAIMER
}

This report was prepared as an account of work sponsored by an agency of the United States Government. Neither the United States Government nor any agency thereof, nor Battelle Memorial Institute, nor any of their employees, makes any warranty, express or implied, or assumes any legal liability or responsibility for the accuracy, completeness, or usefulness of any information, apparatus, product, or process disclosed, or represents that its use would not infringe privately owned rights. Reference herein to any specific commercial product, process, or service by trade name, trademark, manufacturer, or otherwise does not necessarily constitute or imply its endorsement, recommendation, or favoring by the United States Government or any agency thereof, or Battelle Memorial Institute. The views and opinions of authors expressed herein do not necessarily state or reflect those of the United States Government or any agency thereof.

\author{
PACIFIC NORTHWEST NATIONAL LABORATORY \\ operated by \\ BATTELLE \\ for the \\ UNITED STATES DEPARTMENT OF ENERGY \\ under Contract DE-AC05-76RL01830
}

Printed in the United States of America
Available to DOE and DOE contractors from the Office of Scientific and Technical Information,
P.O. Box 62, Oak Ridge, TN 37831-0062;
ph: (865) 576-8401
fax: $(865)$ 576-5728
email: reports@adonis.osti.gov

\begin{abstract}
Available to the public from the National Technical Information Service, U.S. Department of Commerce, 5285 Port Royal Rd., Springfield, VA 22161 ph: (800) 553-6847 fax: $(703) 605-6900$ email: orders@ntis.fedworld.gov online ordering: http://www.ntis.gov/ordering.htm
\end{abstract}

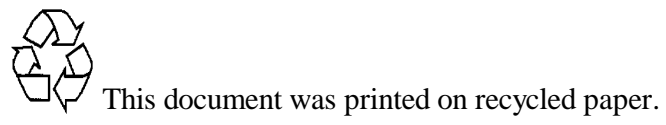




\section{UNCLASSIFIED}

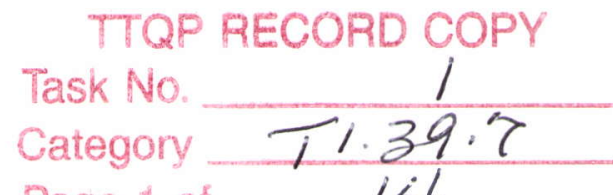

Page 1 of

15

\begin{tabular}{|l|l|}
\hline \multicolumn{1}{|c|}{ TTP Design Analysis Report } & EDP: $\quad \frac{\text { D01398-EDP03 Rev. } 13}{\text { TTQP-1- } 112}$ Rev. $\underline{13}$ TP.76997 \\
\hline $\begin{array}{l}\text { Title: WBN-1 Cycle 10 TPBAR Tritium Release, } \\
\text { Deduced From Analysis Of RCS Data }\end{array}$ & $\begin{array}{l}\text { Number: TTP-1-3046-00 } \\
\text { Revision: 0 }\end{array}$ \\
\hline
\end{tabular}

Purpose and Description of Design Analysis:

This document contains the calculation of the TPBAR tritium release from the Mark 9.2 design

TPBARs irradiated in WBN cycle 10. The calculation utilizes the generalized cycle analysis methodology given in TTP-1-3045 Rev. 0.

Changes to Previous Proven Designs or the Analysis of Previous Proven Designs:

The calculation is for cycle 10 of WBN-1 and utilizes the generalized cycle analysis methodology given in TTP-1-3045 Rev. 0. (Shaver et al., 2011), which is an updated methodology from what was outlined in TTP-1-3016 (Shaver et al., 2010). Updates included in the analysis method are the incorporation of the updated calculations for tritium production from soluble species in the RCS TTP-1-3001 Rev. 1 (Shaver, 2011a) and the updated secondary source calculation TTP-1-3009 Rev. 2 (Shaver, 2011b), as well as the latest tritium concentration uncertainty report TTP-1-3043 (Baldwin et al., 2011).

Unverified Assumptions and/or Unverified Inputs (including source identification if available): The $2.5 \%$ uncertainty on water injection data is assumed. Instantaneous release from secondary sources is also an assumption. It was concluded in TTP-1-3016 (Shaver et al., 2010) that RCS nonTPBAR reactor component tritium sources are dominated by release of tritium from secondary neutron source rods, with minor contributions from fuel rods, IFBAs, and control rods. This was based on finding statistically negligible amounts of "unaccounted tritium" from several non-TPBAR WBN and SQN for cycles analyzed by the new methodology. In those cycles the tritium production of secondary source rods could be calculated accurately, and the total RCS tritium and concentrations of soluble tritium sources were monitored carefully. The $5.82 \%$ uncertainty on tritium is still a draft.

Method of Analysis:

Computer Codes used including Version and Computer Processor(s) or Model(s) Used:

EXCEL 2011 spreadsheet calculations and curve-fitting on a Intel PC under Windows 7.

Summary of Results:

The results of calculation to determine the TPBAR tritium release in cycle 10 are shown in plots and discussed in Section 4. The curve fit for the cycle 10 release is:

fit Cumulative TPBAR Release $(C i / T P B A R)=\frac{6.3804718}{1+\left(\frac{E F P D}{413.89918}\right)^{-2.916337}}$

\begin{tabular}{|c|c|c|}
\hline & Signature & Date \\
\hline $\begin{array}{l}\text { Responsible Engineer(s) } \\
\text { MW Shaver, MT Niehus }\end{array}$ & Mouk Wo shom & $\begin{array}{l}10 / 3 / 2011 \\
10 / 3 / 2011\end{array}$ \\
\hline Design Verifier(s) & & $10 / 114 / 11$ \\
\hline TTP ADC & 0 & $10 / 18 / 11$ \\
\hline $\begin{array}{l}\text { Design Database Administrator } \\
\text { NL Mara }\end{array}$ & & \\
\hline Quality Engineer & shomparimen & $10 / 7 / 2011$ \\
\hline $\begin{array}{l}\text { Design Task Manager } \\
\text { EF Love, Jr. }\end{array}$ & & स्याn \\
\hline
\end{tabular}

Caution: All users of this document should contact the PNNL TTP Project Assistant to ensure possession of the most current revision. 


\section{WBN-1 CYCLE 10 TPBAR TRITIUM RELEASE, DEDUCED FROM ANALYSIS OF RCS DATA}

\subsection{INTRODUCTION}

This document contains reactor coolant system (RCS) tritium activity data, analysis, and qualification for Watts Bar Nuclear Unit 1 (WBN) cycle 10, which included 240 Mark 9.2 design TPBARs featuring full-length getters (FLGs). The purpose of the RCS tritium activity data analysis is to estimate and quantify the amount of tritium attributable to permeation-type release from the TPBARs. The reactor power history for cycle 10 is shown in Figure 1.1. The cycle extended from October 20, 2009 to April 4, 2011 (532 calendar days; 513 EFPD), for a burnup of $19,950 \mathrm{MWd} / \mathrm{MT}$. The cycle included two brief unplanned shutdowns for a couple of days each, plus two power setbacks below $40 \%$. There was also a coast-down in power for the last month of the cycle. No TPBAR failures were indicated by the RCS tritium activity history.

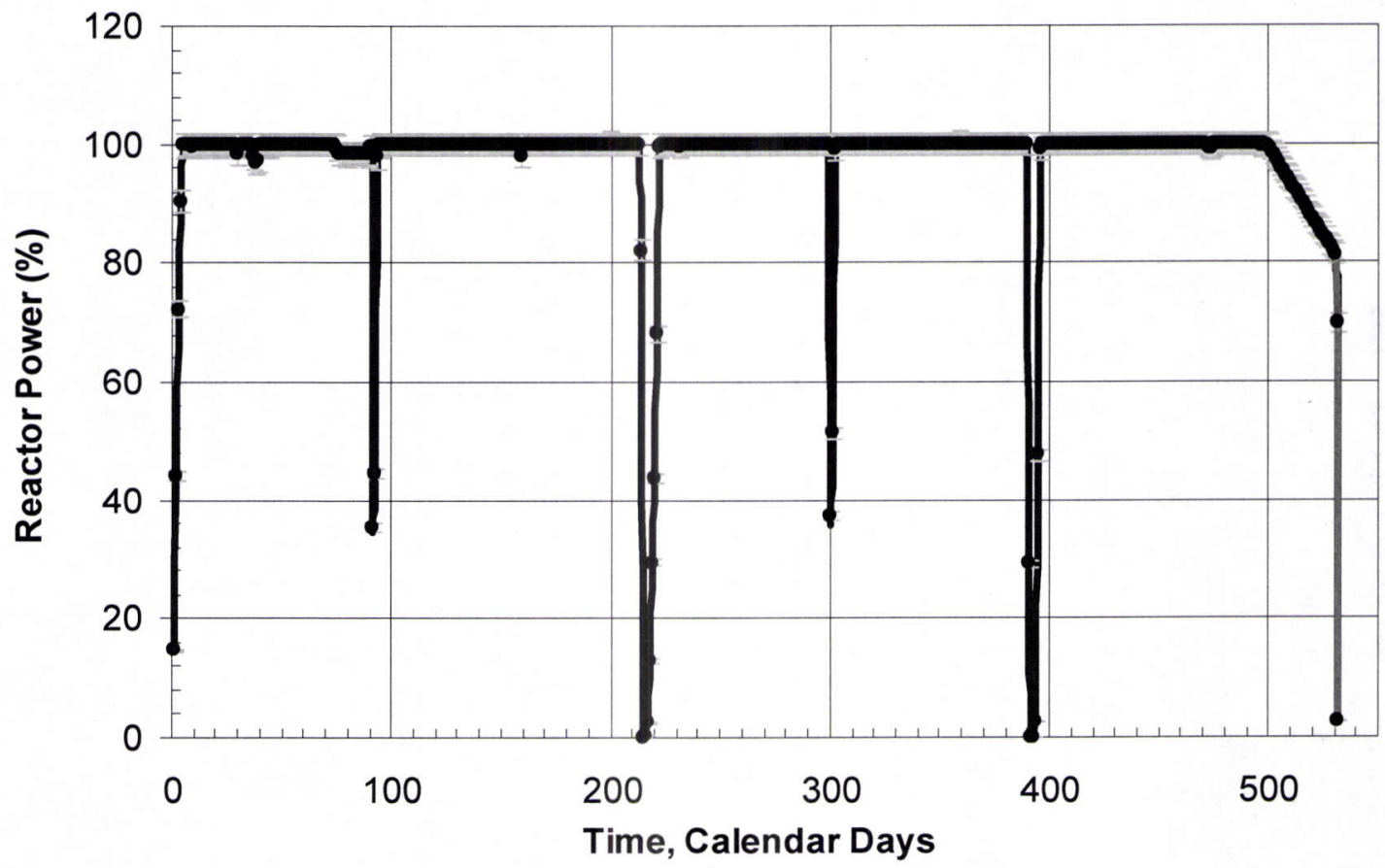

Figure 1.1. Reactor Power History for Cycle 10

The RCS tritium data analysis method (by which the cumulative total TPBAR tritium release is deduced from the cumulative total tritium in the RCS) has also been updated and can be found in TTP-1-3016 (Shaver 2010). Updates included in the analysis method are the incorporation of the updated calculations for tritium production from soluble species in the RCS TTP-1-3001 Rev. 1 (Shaver 2011a) and the updated secondary source calculation TTP-1-3009 Rev. 2 (Shaver 2011b), as well as the latest tritium concentration uncertainty report TTP-1-3043(Baldwin et al 2011).

\section{UNCLASSIFIED}




\section{UNCLASSIFIED}

The use of the estimated upper-bound TPBAR tritium release rate constrains the number of TPBARs per cycle to undesirably low values. If the number of TPBARs needed cannot be met in one reactor with current releases and limits, then more reactors would be needed to irradiate TPBARs. In order to minimize the number of reactors required the estimation process for the TPBAR release rate ,described in TTP-1-3045 (Shaver et al., 2011) should be reviewed very critically, and updated as further irradiation experience is gained.

In particular, the deduced TPBAR tritium release rate could be significantly overestimated if the RCS contributions from non TPBAR core components (fuel rods, Integral Fuel Burnable Absorber rods (IFBA's), Wet Annular Burnable Absorber rods (WABA's), and control rods) are underestimated. Further research and understanding of the non-TPBAR core component tritium production and release will serve to ensure margin to release rate limits (through reduced uncertainty bounds). Such efforts may increase the number of TPBARs allowed in a cycle enough that the number of required reactors can be reduced.

The measured tritium concentration history and the water injection history are described in Section 2. The non-TPBAR sources of tritium in the coolant are quantified and described in Section 3. The results of the data analysis procedures, as documented in TTP-1-3045 (Shaver et al., 2011) used to calculate the estimated TPBAR release using the data from sections 2 and 3 is then discussed in Section 4. References are given in Section 5. 


\section{UNCLASSIFIED}

\subsection{RCS TRITIUM ACTIVITY DATA AND WATER INJECTION DATA}

\subsection{TRITIUM CONCENTRATION HISTORY, AND ESTIMATED UNCERTAINTIES}

In cycle 10, the RCS water was sampled and analyzed for tritium activity 3 times per week through November 2010 and then daily after that, and reported as microCi/gram of water. Linear interpolation between consecutive data points was used to obtain daily values of the tritium activity. The reported tritium concentration data, which were found to have no bias TTP-1-3043 (Baldwin et al., 2011) are plotted vs. time-in-cycle for cycle 10 in Figure 2.1.

The sudden reductions in concentration at various times are due to reactor shutdowns or power setbacks. During a reactor shutdown, the RCS soluble boron concentration is greatly increased to provide shutdown (criticality) reactivity margin. This elevated boron concentration must be diluted to the previous lower levels during the startup following the shutdown. This requires a large quantity of water to be injected, which also dilutes the tritium concentration. For reference, the boron and lithium concentration history for cycle 10 is shown in Figure 2.2.

\subsubsection{Estimated Uncertainties in Tritium Activity Reported Data}

The uncertainty of the measurement technique is based on (Baldwin et al., 2011), the two-sigma uncertainty for cycle 10 data is estimated as $5.82 \%$ relative. This makes the $90 \%$ confidence level $4.79 \%$ relative. 


\section{UNCLASSIFIED}

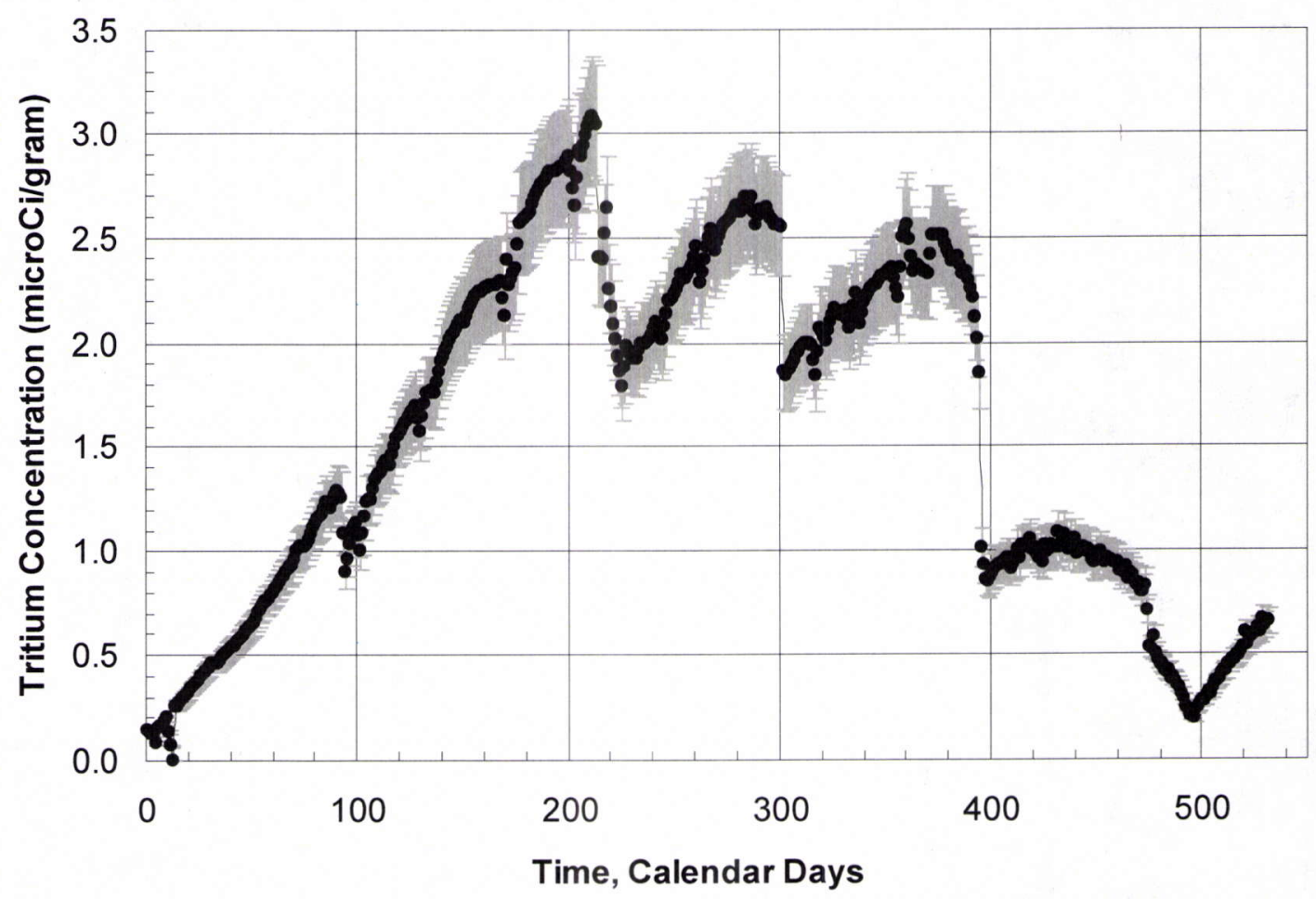

Figure 2.1. Cycle 10 Tritium Activity Data. Drops occur at shutdowns (compare to Figure 1.1.).

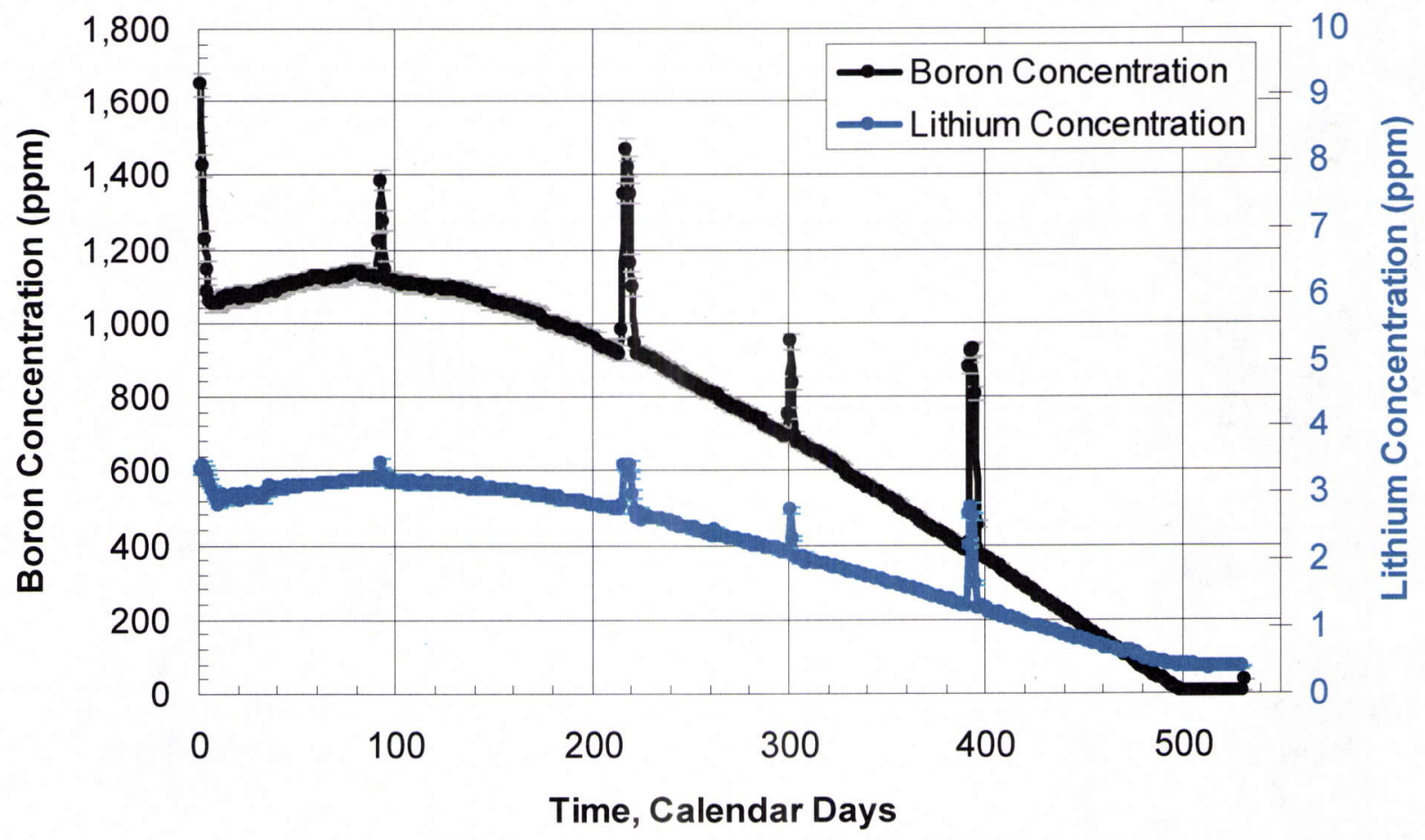

Figure 2.2. Cycle 10 Soluble Boron and Lithium Concentrations. Spikes occur at shutdowns (compare to Figure 1.1.). 


\subsection{RCS WATER MASS, INJECTION RATES, AND ESTIMATED UNCERTAINTIES}

The RCS water volume applicable to cycle 10 is 12,022 cubic feet at $586.2^{\circ} \mathrm{F}$ [see MCI.6: RCS volume in (Starner, 2009)]. The corresponding RCS water mass is $2.41 \mathrm{E} 8$ grams. The daily reported boron solution and water injections for cycle 10, including the very large water additions during shutdowns, are shown in Figure 2.3. The cumulative water additions are assumed to be matched by water withdrawals from the RCS. The cumulative water and boric acid injections are shown in Figure 2.4, both in cumulative gallons and in percentage of the cold RCS volume. As can be seen, roughly eight "core loads" of water were moved through in cycle 10 .

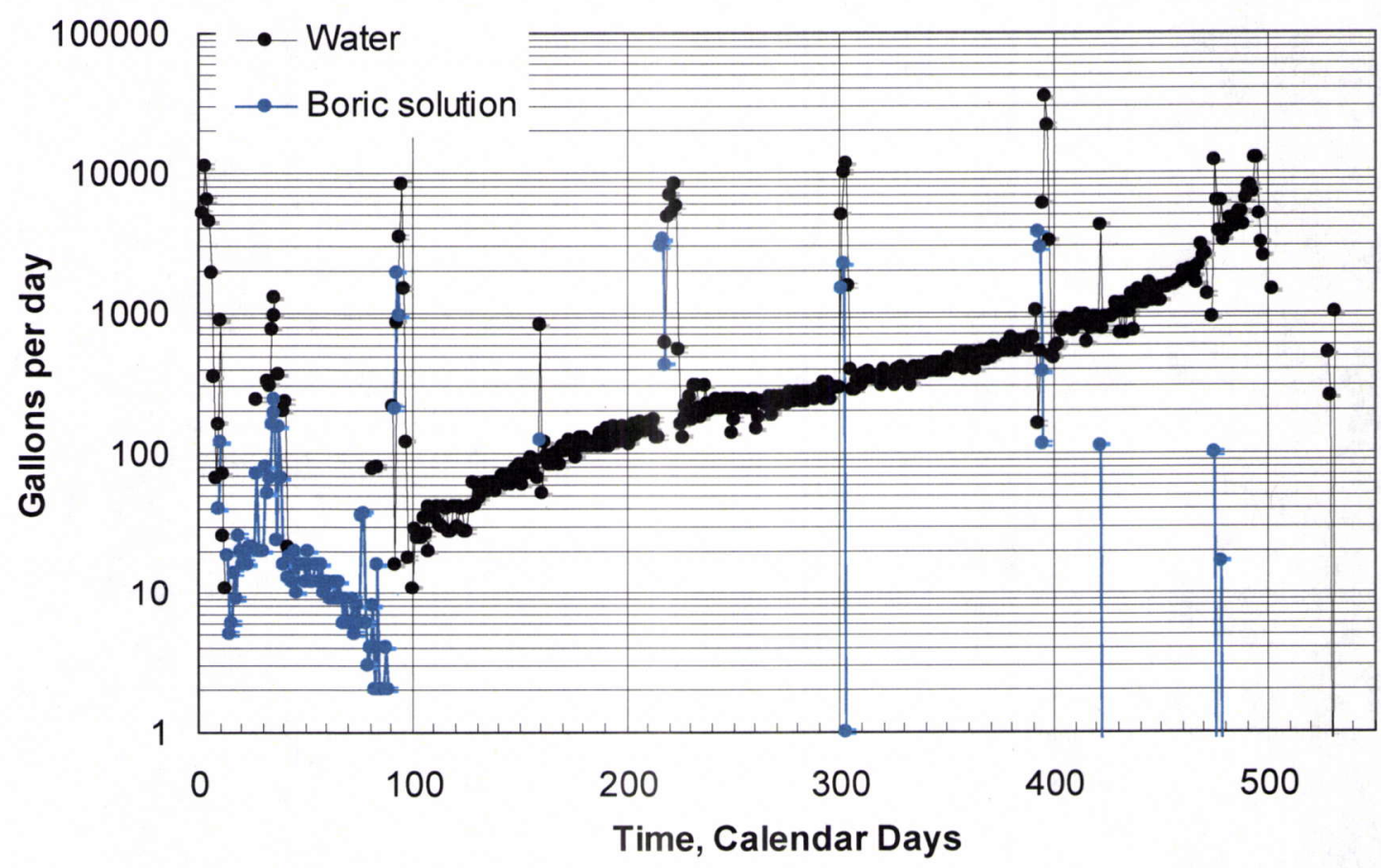

Figure 2.3. Water and Boron Solution Injections for Cycle 10. Spikes are due to large water injections during shutdowns (compare to Figure 1.1.). 


\section{UNCLASSIFIED}

TTP-1-3046

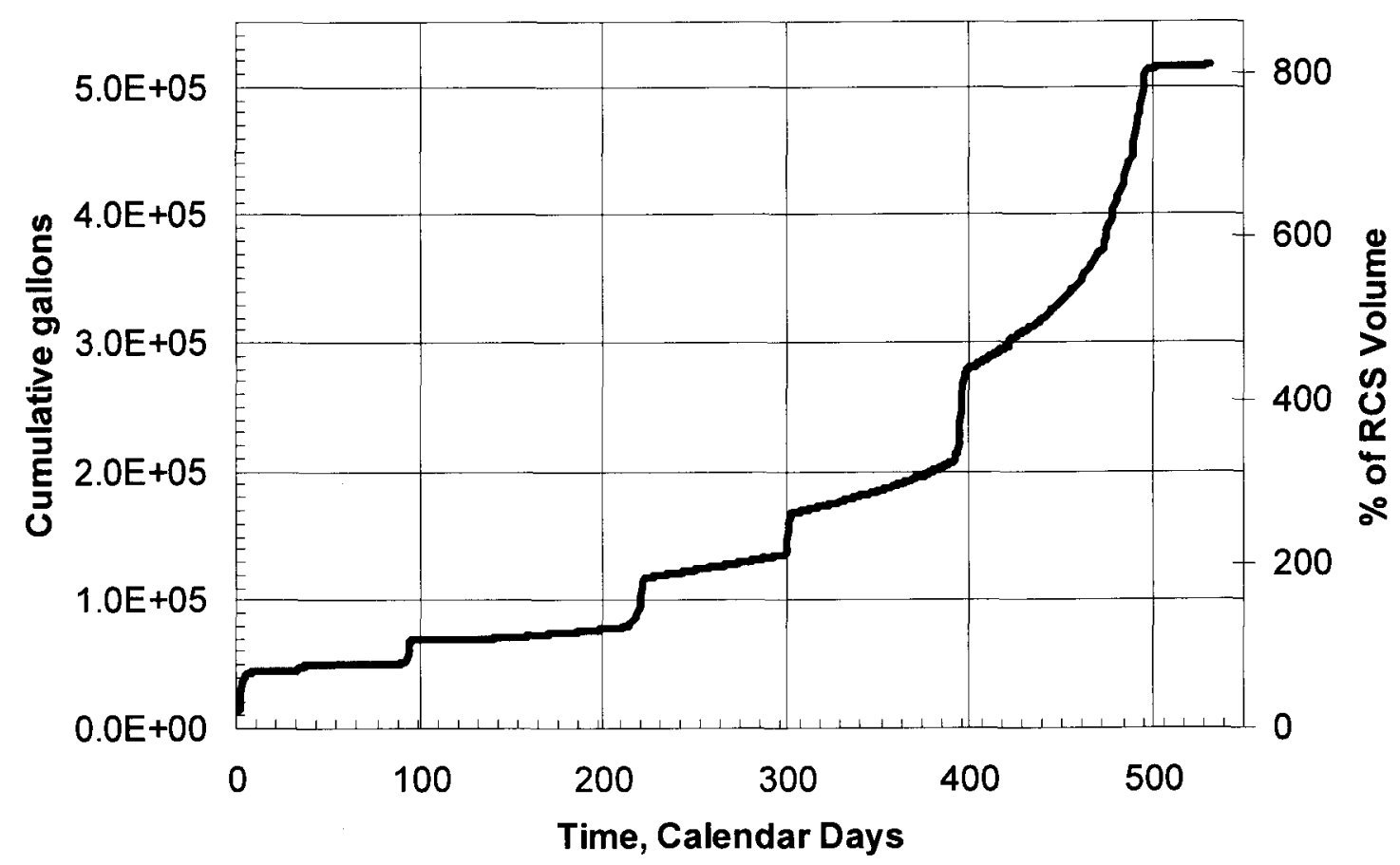

Figure 2.4. Cycle 10 Cumulative Water Additions. Step changes in cumulative values are due to large water injections during shutdowns (compare to Figure 1.1.).

\subsubsection{Estimated Uncertainties in Water Injection Data}

Based on private communication with TVA personnel, the water injection and total volume uncertainties are, "not more than a couple percent". To not underestimate, an uncertainty of $2.5 \%$ relative has been assigned to these data.

\subsection{VERIFICATION OF CYCLE 10 RCS TRITIUM ACTIVITY DATA}

As can be seen in the plots above, at the end of the cycle so much water is moved through the core that the tritium concentration in the RCS is diluted to very small quantities. Therefore, at the end of the shutdown after the cycle the plant had released almost all tritium produced to the environment. The tritium effluent measurement is independent of the tritium concentration and water movement data, and is be used as an independent measure of the tritium in this RCS calculation. Essentially, at the end of cycle 10, the amount of tritium calculated to being in the RCS should be roughly equal to, or a little greater than the amount of tritium released from the plant by the end of the outage following the cycle. This is shown to be the case in Figure 2.5 below.

\section{UNCLASSIFIED}




\section{UNCLASSIFIED}

TTP-1-3046

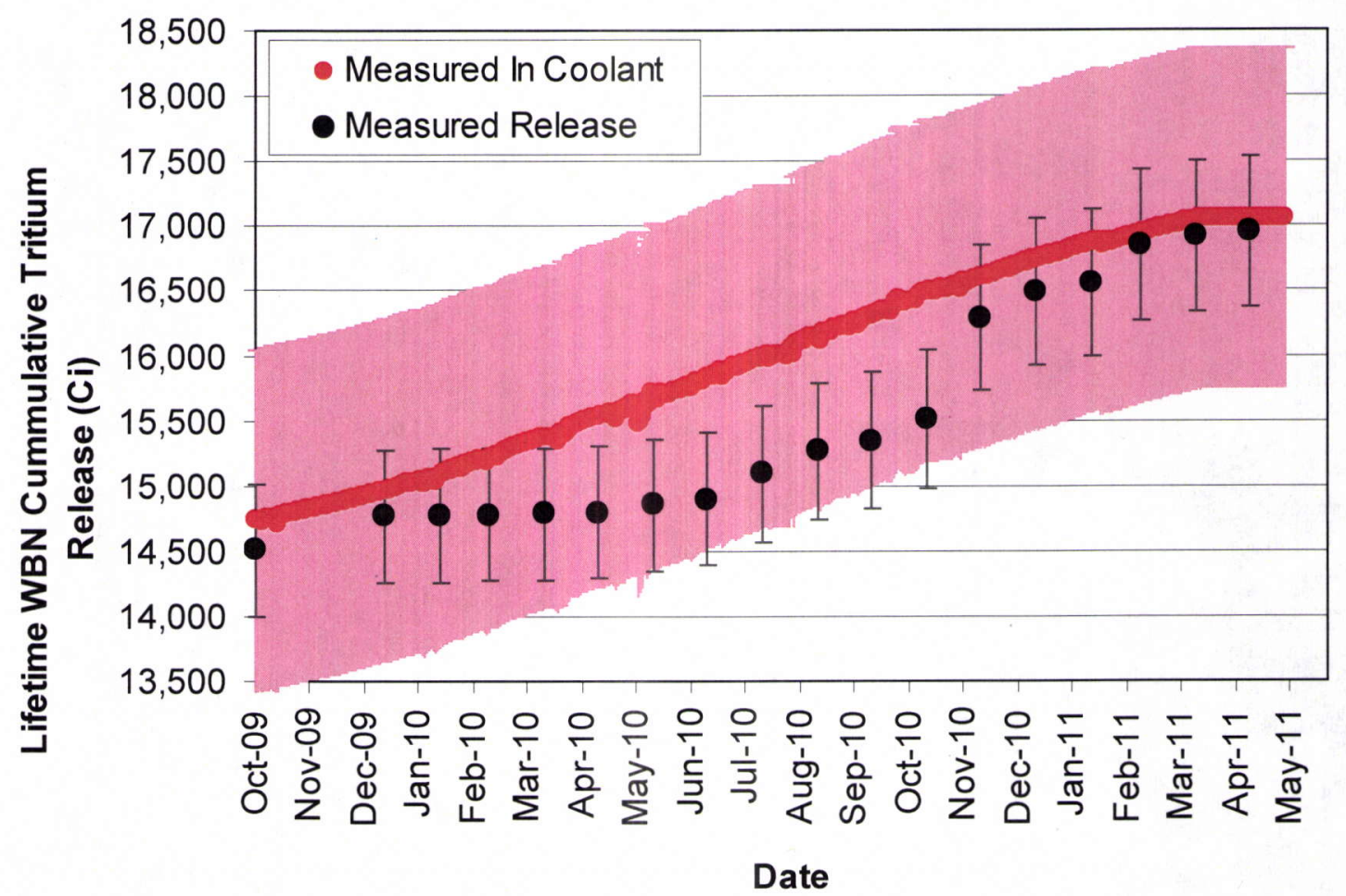

Figure 2.5. Comparison of Tritium Calculated to be in the RCS and Tritium Measured as Released from WBN for Cycle 10. 


\subsection{NON-TPBAR SOURCES OF TRITIUM IN THE RCS}

The non-TPBAR sources include the tritium produced from soluble boron, lithium, and deuterium, as well as the tritium produced and released to the RCS from tritium-producing nonTPBAR core components. The tritium release from non-TPBAR components is now concluded to be nearly $100 \%$ from the secondary neutron source rods. Support for this conclusion and the method for applying these source terms to project cumulative RCS tritium (without TPBARs) is described in TTP-1-3016 (Shaver et al., 2010). The tritium from all non-TPBAR sources except for secondary sources are discussed in section 3.0 of TTP-1-3045 (Shaver et al., 2011).

\subsection{TRITIUM RELEASE FROM SECONDARY SOURCES}

The Cycle 10 dependent tritium production from secondary sources is taken from TTP-1-3009 Rev. 1. (Shaver, 2011b). The cycle specific correlation of the analytical results for Cycle 10 of $\mathrm{WBN}$ is as follows:

$$
\text { Cycle } 10 \text { Activity }[\mathrm{Ci}]=1.9636 \mathrm{E}-12 * \mathrm{~B}^{3}+3.7207 \mathrm{E}-08 * \mathrm{~B}^{2}+1.7862 \mathrm{E}-02 * \mathrm{~B}
$$

where, B is the average fuel burnup in the secondary source host assemblies. The average burnup of the secondary source host assemblies was 22,700 MWd/MTU [BOC: 25,000 MWd/MTU (Augustine et al., 2009) to EOC: 47,700 MWd/MTU (Augustine et al., 2011)]. The average core burnup was determined to be $19,950 \mathrm{MWd} / \mathrm{MTU}$ for cycle 10 , so the secondary source host assemblies had $13.8 \%$ higher burnup than core average. 


\section{UNCLASSIFIED}

\subsection{CALCULATION OF TPBAR TRITIUM RELEASE AND ASSOCIATED UNCERTAINITES}

This section describes the results of the application of the methodology from TTP-1-3045 (Shaver et al., 2011) to the calculation of Mark 9.2 TPBAR tritium release for Cycle 10, by analyzing the data presented in earlier sections of this calculation. The $90 \%$ confidence interval on this release is also calculated to determine the $95 \%$ upper bound confidence level.

\subsection{CUMULATIVE TPBAR TRITIUM RELEASES}

The Cycle 10 total cumulative RCS tritium and its assignment to individual sources is shown in Figure 4.1. It corresponds with an annual TPBAR release rate (averaged over the last 365 EFPD of each cycle) of $3.8 \pm 0.8 \mathrm{Ci} / \mathrm{TPBAR} /$ year, so the $95 \%$ confidence level upper bound was calculated to be $4.6 \mathrm{Ci} / \mathrm{TPBAR} / \mathrm{year}$. The fractions estimated from each of the sources are also shown below in Figure 4.2. Note that because tritium is typically released from the TPBARs almost exclusively during the final year of the cycle.

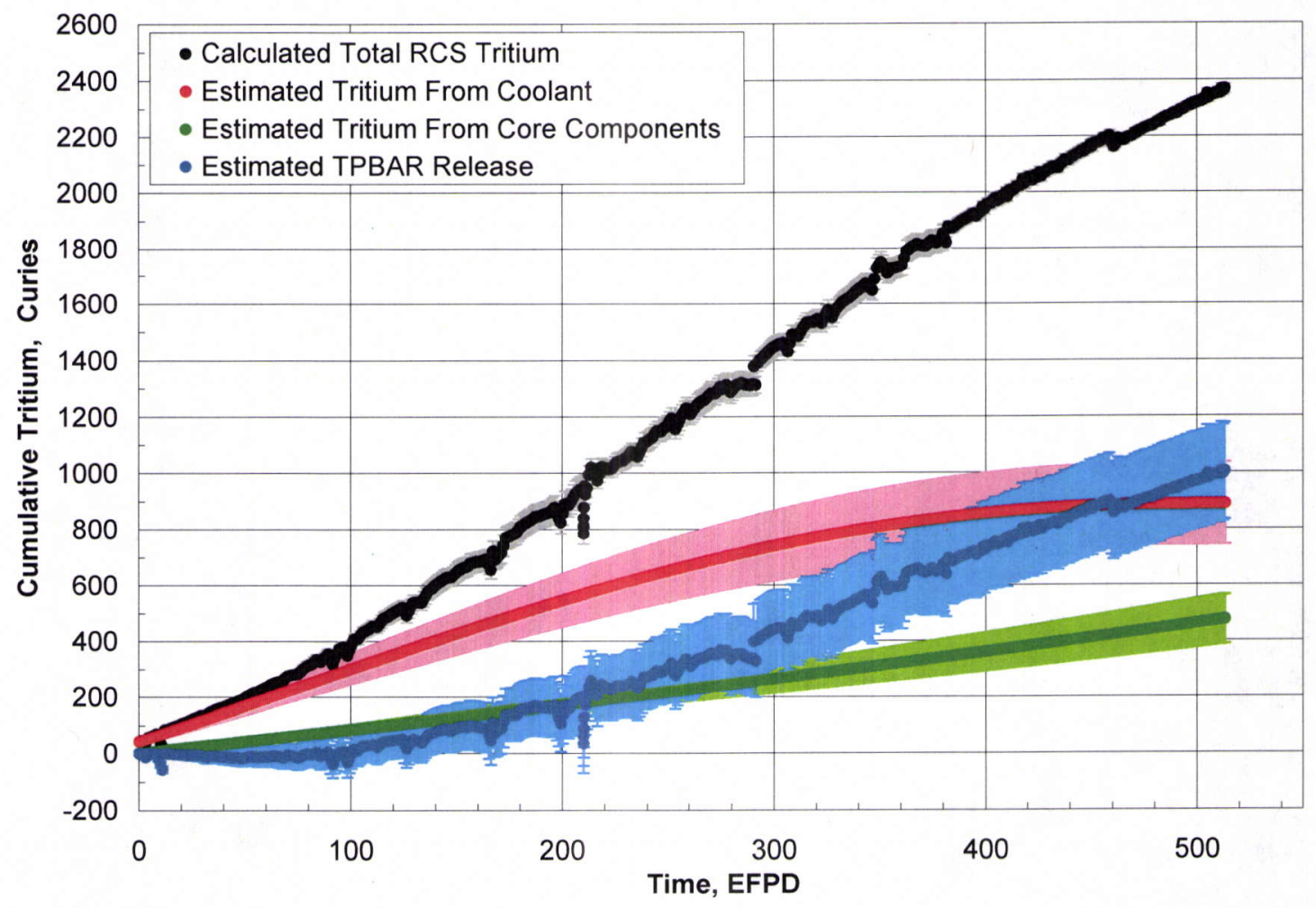

Figure 4.1. Cycle 10 RCS Total Cumulative Tritium, and Estimated From Individual Sources.

\section{UNCLASSIFIED}




\section{UNCLASSIFIED}

TTP-1-3046

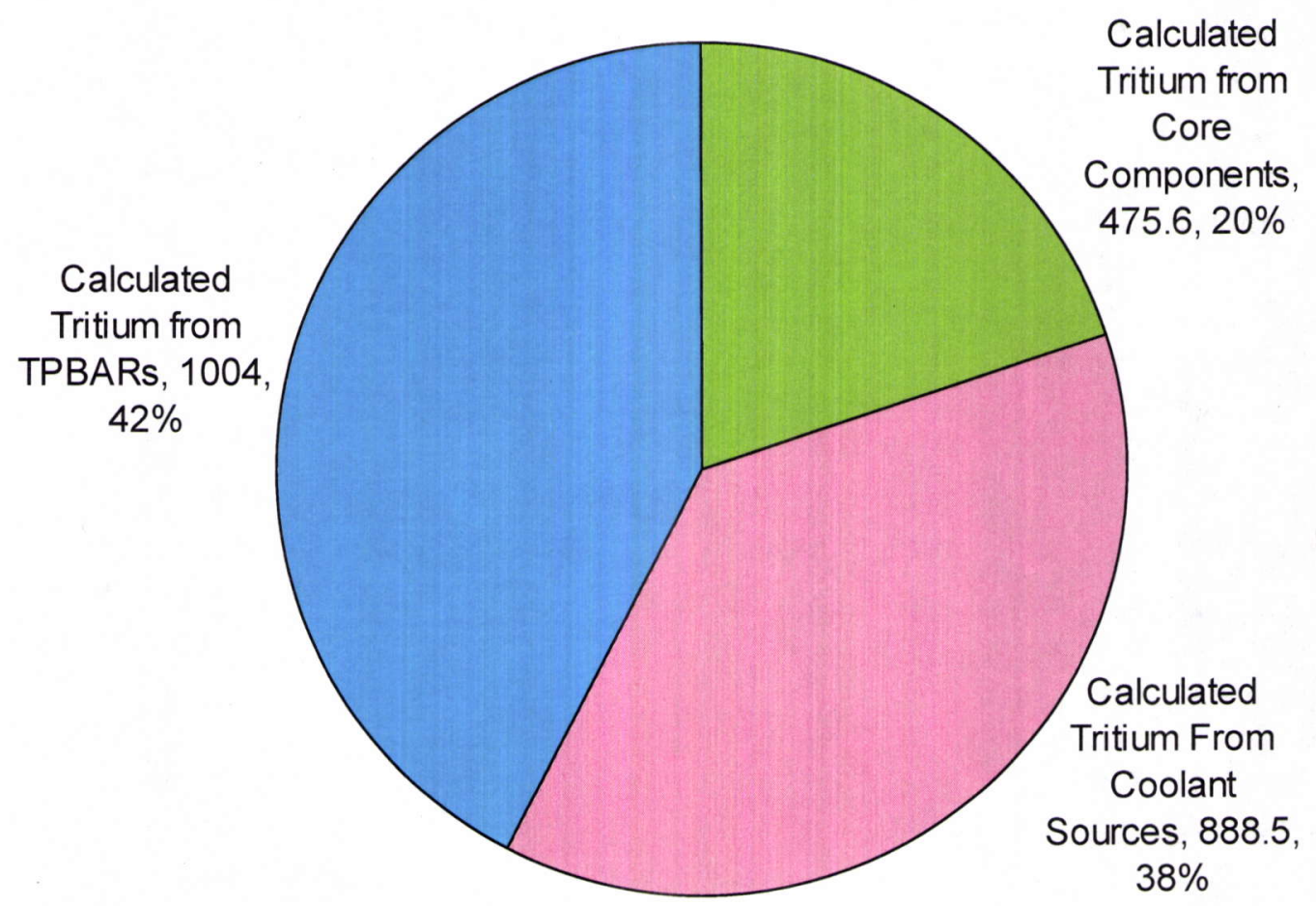

Figure 4.2. Cycle 10 RCS Estimated Tritium Source Contributions.

The total cumulative TPBAR tritium release per TPBAR shown in Figure 4.3 as a function of EFPD. Note that the smooth nature of the deduced TPBAR tritium release indicates that there were no TPBAR cladding failures. Even a single failure would have caused a very significant upward jog this curve. However, there does appear to be some discrepancies in the data. There are large, brief, deviations in the cumulative curve throughout the cycle. The largest is on EFPD 292 , where there is a $23 \%$ increase in the cumulative release. There is also an unexplained decrease in the cumulative curve (which is clearly non-physical) around EFPD 460, which is during the time when daily tritium data was being taken and reported.

A curve fit was taken on the deduced TPBAR release curve for cycle 10 with TPBARs using the TableCurve2D software, to better analyze the tritium release per TPBAR. The class of curve fits that fit all of the cycles the best is the cumulative (or sigmoidal functions). This makes sense as those functions are used frequently for diffusion or permeation type analyses. The fit that worked the best for all cycles and preserved certain physical features that are known was the Logistic Dose Response Curve. The physical features preserved are the zero intercept (meaning the release at the beginning of the cycle is zero), zero derivative intercept (meaning the release rate at the beginning of the cycle is zero), and no negative values. The equation for the curve fit is below in Equation 4.1.

$$
\text { Cumulative TPBAR Release }(C i / T P B A R)=\frac{6.3804718}{1+\left(\frac{E F P D}{413.89918}\right)^{-2.916337}}
$$

\section{UNCLASSIFIED}




\section{UNCLASSIFIED}

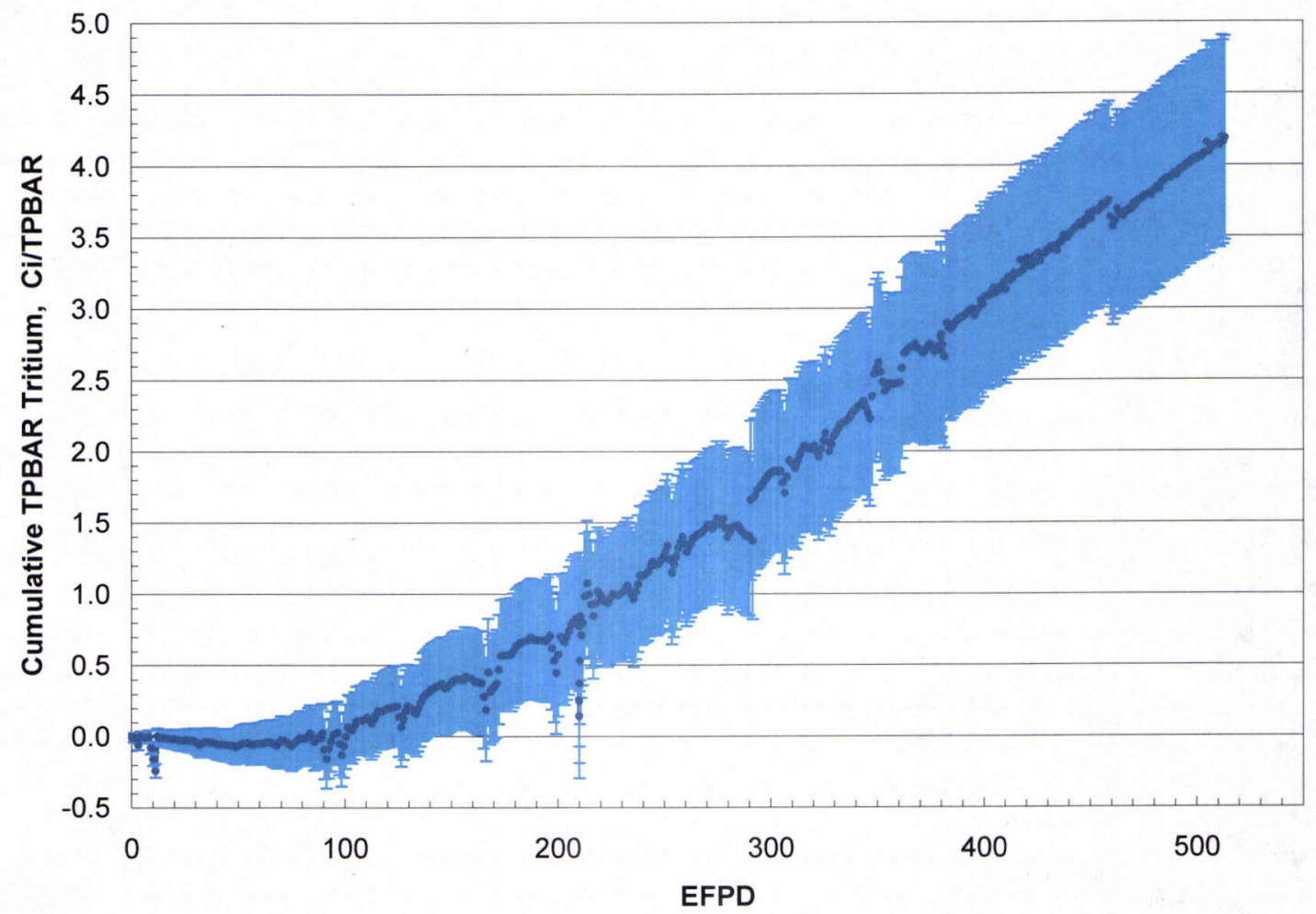

Figure 4.3. Cycle 10 Tritium Release per TPBAR and 90\% Uncertainty Bars.

\subsection{UNCERTAINTY AND TPBAR TRITIUM UPPER BOUND CALCULATIONS}

The Cycle 10 uncertainty is calculated per the methodology documented in TTP-1-3045. The end of cycle release for cycle 10 was calculated to be $4.2 \pm 0.7 \mathrm{Ci} / \mathrm{TPBAR} / \mathrm{year}$. The bounding annual tritium release rate for cycle 10, averaged over the last year of the cycle, is calculated to be $3.8 \pm 0.8 \mathrm{Ci} / \mathrm{TPBAR} /$ year.

The fraction of the total variance (on TPBAR release) represented by the various contributions are plotted in Figure 4.4 together with the total variance. As can be seen the variance in the coolant sources calculation is the major source of uncertainty (an average of $79 \%$ of the total variance), while the non-TPBAR core component calculation is the second largest fraction (at an average of $13 \%$ ) and the remaining variance from the calculated total RCS tritium (with an average of $8 \%$ ). 


\section{UNCLASSIFIED}

TTP-1-3046

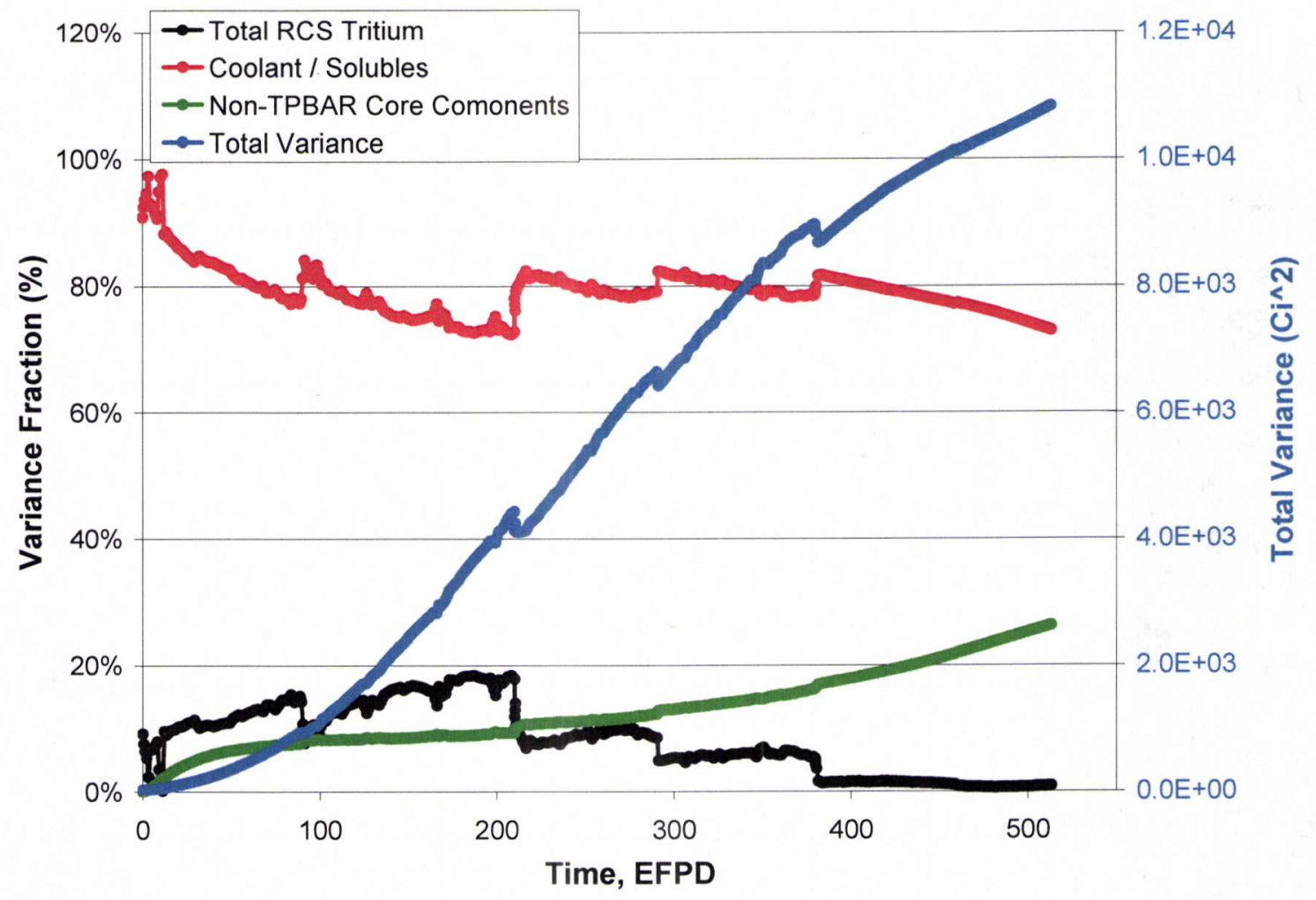

Figure 4.4. Fractional Contributions to Variance (and Total Variance) on the Cycle 10 TPBAR Cumulative Release 


\section{UNCLASSIFIED}

TTP-1-3046

\subsection{REFERENCES}

Augustine, D.J., Hulme J.G., Neumann J.D, Blanco A.J., Keckler K.J., Staum C.J., Chapman, D.M., McGrew J.J., and G.T. Wolfram. Nuclear Parameters and Operations Package for Watts bar Unit 1, Cycle 10. WCAP-17118-P Rev. 2, Westinghouse Electric Corporation, December 2009.

Augustine, D.J., Brammer D.P., Cahill T.J., Durham B.G., Hulme J.G., Lasswell K.T., Mansfield L.A., Sugimoto M.A., and Wolfram G.T. Nuclear Parameters and Operations Package for Watts bar Unit 1, Cycle 11. WCAP-17401-P Rev. 0, Westinghouse Electric Corporation, April 2011.

Baldwin D.L., K.K. Anderson, and D.S. Coffey, 2011. 2011 WBN RCS Tritium Measurement Uncertainty, TTP-1-3043, revision 0, Pacific Northwest National Laboratory, Richland, WA.

Shaver, M.W, DD Lanning, and KK Anderson. 2010. MARK 9.2 (FLG Design) TPBAR Tritium Release, Deduced From Analysis And Qualification Of WBN Cycle 9 RCS Data. TTP-13016, Pacific Northwest National Laboratory, Richland, Washington.

Shaver, M.W. 2011 a. Tritium Production in an LWR Reactor Coolant System. TTP-1-3001 Revision 1, Pacific Northwest National Laboratory, Richland, Washington.

Shaver, M.W. 2011 b. Tritium Production in Secondary Startup Neutron Sources. TTP-1-3009, Revision 2, Pacific Northwest National Laboratory, Richland, Washington.

Shaver, M.W. and M.T. Niehus. 2011. TPBAR Tritium Release Calculation Methodology. TTP-1-3045, Revision 0, Pacific Northwest National Laboratory, Richland, Washington.

Starner, J.P., 2009. Watts Bar Unit 1, cycle 10 TPBAR Design Inputs, TTP-1-187, Revision 1, Pacific Northwest National Laboratory, Richland, Washington. 